\title{
The precision in estimating the stem volume in Smilde forest management unit
}

\author{
J. J. JANSEN \\ Forestry Department, Wageningen Agricultural University, P.O. Box 342, NL 6700 AH \\ Wageningen, Netherlands
}

Received 21 May 1990; accepted 6 September 1990

\begin{abstract}
The volume of the growing stock of a management unit and its precision were estimated with double sampling. A national standard volume table was used and a local volume table is constructed.

Keywords: forest inventory, double sampling, weighted regression, standard volume table, local volume table

\section{Introduction}

In the 1800 ha forest management unit Smilde (Netherlands) the stem volume of the growing stock was estimated by double (or two-phase) sampling. In Phase 1, a systematic sample scheme was used to estimate the number of trees per diameter class. In Phase 2, the relation between diameter and volume was examined with linear regression. Both phases together gave the volume estimate (per ha). The tree volume (Phase 2) was not directly observed in the field, but deducted from the Dutch standard volume tables (Dik, 1984) with the measured tree parameters: species, diameter and height. Herewith an out-place element was introduced in an in-place forest inventory. This synopsis describes the precision of this procedure.

This method of forest inventory of a management unit is a new combination of well known sample procedures. However for national forest inventory, many comparable methods are known. In Western Europe at this moment, the leading concept is a forest-stand inventory with unknown precision. However at several places forest inventory methods for management units without standwise information were introduced, in the Netherlands e.g. in the Zeist forest management unit (Sevenster, 1986).
\end{abstract}




\section{J. J. JANSEN}

\section{Materials and methods}

\section{Sampling design}

The sampling design of Phase 1 was a systematic one, using a grid of one dot per $4 \mathrm{ha}$, with a circular plot at each dot. The plot size was $201 \mathrm{~m}^{2}$ in young stands and $707 \mathrm{~m}^{2}$ in old stands. On borderline plots the net forest area was measured. The plots were used as elementary sample units, in fact they were clusters of the real elementary units (the trees). The elementary statistical characteristics were volume and number of trees per ha for each class, defined by $1-\mathrm{cm}$ diameter class and tree species. The procedure results in unbiased population estimates in the case of sampling with probability proportional to the plot size (pps). This is true for inforest plots drawn at random. Schmid (1969) showed that bias will be introduced for borderline plots, and also that this bias is negligible. The Smilde inventory can be considered to be a pps procedure. For the estimation of variance, the systematic sample plots were considered to be drawn at random.

In Phase 2 of the sampling scheme, one randomly chosen tree per plot was sampled for height. The probability of drawing this tree is proportional to the reciprocal of the number of trees per ha in the plot, which is strongly correlated with tree diameter. Tree volume was assessed using a standard volume table (Dik, 1984).

\section{Estimation of the number of trees}

In Phase 1, the number of trees per ha in a subpopulation and its variance were according to Cochran (1977) and de Vries (1986) estimated by:

$$
\underline{\hat{N}_{\mathrm{k}}}=\frac{\sum_{i=1}^{n} N_{k i}}{n}=\frac{\sum_{i=1}^{n} M_{k i} / a_{i}}{n}
$$

where:

$N_{k} \quad=$ number of trees per ha of subpopulation $k$

$n \quad=$ number of forest plots

$M_{k i}=$ number of trees of subpopulation $k$ in $i^{\text {th }}$ plot

$N_{k i}=$ number of trees per ha of subpopulation $k$ in $i^{\text {th }}$ plot

$a_{i} \quad=$ forest area of the $i^{\text {th }}$ plot in ha

$k=$ index for subpopulation defined by species group and diameter class.

$$
\text { vâr } \underline{\hat{N}}_{k}=\frac{\sum N_{k i}{ }^{2}-n \cdot \hat{N}_{k}^{2}}{n(n-1)}
$$

\section{Volume tariff}

According to Cunia (1985), tree volume $\left(v_{j}\right)$ is sufficiently described by the heteroscedastic model:

$$
\underline{v}_{j}=\beta_{1} x_{1 j}+\beta_{2} x_{2 j}+\beta_{3} x_{3 j}+\sigma \sqrt{ } w_{j} \underline{e}_{j}
$$


where:

$x_{1 j}=1, x_{2 j}=d_{j}, x_{3 j}=d_{j}^{2}$ and $w_{j}=d_{j}^{4}$

$d_{j}=$ diameter breast height in $\mathrm{cm}$ of $j^{\text {th }}$ tree

$\underline{e}=$ here and else in this synopsis an errorterm with $\operatorname{Exp}(e)=0$ and $\operatorname{Var}(\underline{e})=1$; assumptions on the probability function of this stochastic variable are not necessary.

The model represents a local volume table (or volume tariff). The unequal drawing probabilities of the measured trees were incorporated in the regression weights $(w$ $=d^{4}$ ), but the main reason for the application of weights, was phenomenal. In (3), the $\underline{v}_{j}$-values were substituted by their out-place estimate $\underline{\hat{v}}_{j}$ :

$$
\underline{\hat{v}}_{j}=v_{j}+\delta_{j}+\sigma_{\mathrm{m}} \underline{\underline{e 2}} j
$$

where:

$\sigma_{\mathrm{m}}=$ standard deviation of the volume table

$\underline{e} 2=$ error term independent from $\underline{e}$ (3)

$\bar{\delta}=$ possible bias of the standard volume table for local use

Using (4) in (3) the regression variance must be adjusted for the variance of the volume table:

$$
\sigma_{\mathrm{adj}}=c . \sigma
$$

where the correction factor $c=1+\sigma_{\mathrm{m}}{ }^{2 / \sigma^{2}}$.

The standard volume tables have been developed through (Dik, 1984):

$$
\underline{\ln (v)_{j}}=\alpha_{1}+\alpha_{2} \ln \left(d_{j}\right)+\alpha_{3} \ln \left(h_{j}\right)+\sigma_{\mathrm{m}} \underline{e}_{j}
$$

where:

$d \quad=$ diameter breast height in $\mathrm{cm}$

$h=$ height in $\mathrm{m}$

$v \quad=$ stem volume in $\mathrm{dm}^{3}$

This model has a variance not comparable with the variance of model (3). To compare the variances of model (6) and (3) and for estimating $c$, an auxiliary model (7) was developed to replace model (3) having the same variance dimensions as (6):

$$
\underline{\ln (v)}_{j}=\alpha_{1}+\alpha_{2} \ln \left(d_{j}\right)+\sigma \underline{e}_{j}
$$

Both models (6) and (7) are heteroscedastic in $v$. A value for the correction factor $c$ was deduced from the connected variances.

Based on species and diameter frequencies six tariff groups were distinguished. The six equations (3) are simultaneously given in matrix model: 


$$
\underline{v}=X \beta+\sigma W^{-1 / 2} \underline{e}
$$

where:

$X=n \times 18$ matrix of full column rank

$\beta=18$ dimensional vector with regression coefficients

$W=n \times n$ diagonal matrix with regression weights $d^{4}$

For the estimation of $\beta$ and its variance, the usual formulas were used:

$$
\begin{aligned}
& \underline{b}=\left(X^{\prime} W X\right)^{-1} X^{\prime} W \underline{v} \\
& \text { vâr } \underline{b}=\left(X^{\prime} W X\right)^{-1}\left[\left\{\underline{v}^{\prime} W \underline{v}-\underline{b}^{\prime}\left(X^{\prime} W \underline{v}\right)\right\} /(n-18)\right]
\end{aligned}
$$

\section{Volume estimation}

The volume per ha for 'the species group and diameter' class $k$ was estimated by:

$$
\hat{\underline{V}}_{k}=\underline{p}_{k}{ }^{\prime} \underline{b}
$$

where $p_{k}$ is an 18 dimensional array with Phase 1 estimates.

The $p_{k}$ arrays for individual tariff groups will be different. For example, if $k$ belongs to the first tariff group, $p_{k}$ is given by:

$$
\begin{aligned}
& p_{k 1}=\hat{N}_{k}(\text { from 1) } \\
& p_{k 2}=\left[\sum_{i=1}^{n}\left\{\sum_{c=1}^{n} d_{i c} / a_{i} \mid c \in k\right\}\right] / n
\end{aligned}
$$

where:

$d_{i c}=$ diameter of the $c^{\text {th }}$ tree in the $i^{\text {th }}$ plot

$M_{i}=$ total number of trees in the $i^{\text {th }}$ plot

$$
\begin{aligned}
& p_{k 3}=\left[\sum_{i=1}^{n}\left\{\sum_{c=1}^{M_{i}} d_{i c}{ }^{2 /} a_{i} \mid c \in k\right\}\right] / n \\
& p_{k m}=0, \text { for } m \geqq 4
\end{aligned}
$$

The variance of (11) was estimated according to Cunia (1985), and modified for the volume table variance with the correction factor $\mathrm{c}$ :

$$
\operatorname{vâr} \underline{\hat{V}}_{k}(\operatorname{adj}) \approx b^{\prime} \cdot \operatorname{côv} \underline{p}_{k} \cdot b+c \cdot p_{k}{ }^{\prime} \cdot \operatorname{côv} b \cdot p_{k}
$$




\section{Results and discussion}

The value of 1.3432 for $c$ was found. The total volume was estimated at $140.5 \pm$ $8.0 \mathrm{~m}^{3} \mathrm{ha}$ (with a $2 \sigma$ - confidence interval of about $95 \%$ ). Hence the errorpercentage $(E \%)$ amounts to $100 \times 8.0 / 140.5=5.7$. The calculated precision is reasonable. For underlying classes (subpopulations) the results were poorer, with errorpercentages from 25 till 100.

The estimated variance of the total volume was $15.97 \mathrm{~m}^{6} \mathrm{ha}^{-2}$, of which 14.39 was explained by Phase 1 and 1.58 by Phase 2. From the last 1.18 was explained by the volume tariff and 0.40 by the standard volume table. Although in the Smilde inventory the variance was dominated by Phase 1 variance, still the incorporation of the error of the standard volume table in the error of the volume tariff is compulsory.

For calculating the total volume of a forest management unit of about 2000 ha with a precision of at least $10 \%$, the method is suitable. In Smilde even an inventory with 1 plot per 12 ha would give sufficient results. By way of precausion an inventory with not less than 1 plot per 9 ha (a systematic grid of 300 by $300 \mathrm{~m}$ ) can be recommended.

If an $E \%$ of about 10 or less is considered acceptable for underlying classes, than the Phase 1 sample size must be increased many fold. Before doing so a much less expensive way to increase the precision - stratification based on species and age class - should be examined.

\section{References}

Cochran, W. G., 1977. Sampling techniques. John Wiley and Sons, New York.

Cunia, T., 1985. On the error of biomass estimates in forest inventories. Part 1. Its major components. Paper prepared for the National Forest Inventories in Europe Workshop, University of Freiburg Faculty of Forestry, Freiburg i.Br. German Federal Republic, 10-14 June, 1985.

Dik, E. J., 1984. Estimating the volume of standing timber from some species used in forestry. (In Dutch). Rijksinstituut voor Onderzoek in de Bos- en landschapsbouw 'De Dorschkamp', Wageningen. Band 19-1.

Schmid, P., 1969. Samples at the edge of a forest. (In German.) Mitteilungen Schweizerische Anstalt für das forstliche Versuchwesen 45: 234-318.

Sevenster, J., 1986. Survey for the Zeist forest management plan. (In Dutch). Nederlands Bosbouwtijdschrift 58: 185-190.

Vries, P. G. de, 1986. Sampling theory for forest inventory, A teach-yourself course. Springer-verlag, Berlin.

This synopsis is based on a report entitled 'De nauwkeurigheid van de volumeschatting bij de bosinventarisatie van de boswachterij Smilde' by J. J. Jansen, Forestry Department, Wageningen Agricultural University, 30 pp., 13 tables, 2 figs, 8 refs, in Dutch. Available as paper copy (order R109, $f$ 5, - including postage) at NARD, clo Pudoc, P.O. Box 4, 6700 AA Wageningen (telex 45015 bluwgnl). 